Research Article

\title{
Seawater Desalination Based on a Bubbling and Vacuum-Enhanced Direct Contact Membrane Distillation
}

\author{
Guangfu Cao $\mathbb{D}^{1},{ }^{1}$ Qingfen Ma $\mathbb{D}^{1},{ }^{1}$ Jingru Li, $^{1}$ Shenghui Wang, ${ }^{1,2}$ Chengpeng Wang, ${ }^{2}$ \\ Hui Lu $\mathbb{D}^{3}{ }^{3}$ and Yun Zheng ${ }^{1}$ \\ ${ }^{1}$ College of Mechanical and Electrical Engineering, Hainan University, Haikou, Hainan 570228, China \\ ${ }^{2}$ The Institute of Seawater Desalination \& Multipurpose Utilization, MNR, No. 55, Hanghai Road, Nankai District, \\ Tianjin 300192, China \\ ${ }^{3}$ Institute of Environment and Plant Protection, Chinese Academy of Tropical Agriculture Sciences, Haikou, \\ Hainan 571101, China \\ Correspondence should be addressed to Qingfen Ma; mqf0920@hainanu.edu.cn and Hui Lu; aaaluhui@163.com
}

Received 31 May 2021; Accepted 7 September 2021; Published 5 October 2021

Academic Editor: Gianluca Di Profio

Copyright (C) 2021 Guangfu Cao et al. This is an open access article distributed under the Creative Commons Attribution License, which permits unrestricted use, distribution, and reproduction in any medium, provided the original work is properly cited.

\begin{abstract}
A Bubbling and Vacuum-enhanced direct contact membrane distillation (BVDCMD) is proposed to improve the water production rate of the direct contact membrane distillation (DCMD-)based seawater desalination process. Its heat and mass transfer mechanism are theoretically analyzed, and a CFD model is established, which is verified by the published data. Four types of the noncondensable gas, " $\mathrm{O}_{2}$," "air," " $\mathrm{N}_{2}$," and " $\mathrm{H}_{2}$," are adopted as the bubbling gas, and their process enhancements under different pressure of permeate side, temperature, and $\mathrm{NaCl}$ concentration of feed side and flow velocities are investigated. The results show that the permeate flux increased remarkably with the decrease in the viscosity of the bubbling gas, and hence, " $\mathrm{H}_{2}$ " is the best option for the bubbling gas, with the permeate flux being enhanced by $144.11 \%$ and the effective heat consumption being increased by $20.81 \%$ on average. The effective water production rate of BVDCMD is predicted to be $42.38 \%$ more than that of DCMD, proving its feasibility in the seawater desalination.
\end{abstract}

\section{Introduction}

By 2025 , approximately $70 \%$ of the world's population will face water shortage [1], which has become a major environmental problem. Seawater desalination is one of the earliest and effective methods for water treatment, to provide fresh water for many communities and manufacturers in coastal areas, playing an important role in the economic development of water-deficient countries, such as Asia Pacific, Africa, and the Middle East [2]. With the rapid growth of the world's population and pollution, desalination is increasingly considered necessary and feasible, and thus advanced technologies are constantly emerging, including the membrane distillation (MD).

Basic MD processes include the Direct Contact MD $[3,4]$, the Air Gap MD [5], the Sweeping Gas MD [6], and Vacuum MD $[7,8]$. The major difference among them lies in the concentrating mode of volatile components on the permeation side of the system. MD is less affected by the osmotic pressure than RO, and its energy consumption is less than Multi-stage Flash (MSF). However, it has not been commercialized in large desalination plants due to the technical problems of low flux, membrane wetting, and large heat loss.

Membrane performance (hydrophobicity, antifouling, etc.) has significant influences on the membrane flux, energy consumption, and durability [9-11]. A recent trend in membrane performance improvement has focused on fabricating nanocomposite membranes through the incorporation of nanofillers. Efome et al. [12] developed a doublelayer membrane comprising of a bottom microporous PVDF nanocomposite flat sheet membrane and a top electrospun nanofibre thin layer, with great potential to solve the pore wetting problem. They also fabricated a triple-layered 
DCMD membrane comprising of a hydrophobic top layer, middle layer with a large pore size, and hydrophilic bottom layer for the desalination of salty water, which was tested and proved stable in water and suitable for producing pure water by desalination [13].

Besides the membrane performance improvement, the modification of the operating patterns of $\mathrm{MD}$ is another effective measure to improve the membrane flux and reduce the energy consumption, attracting the attention of many researchers. In Vacuum-enhanced direct contact membrane distillation (VEDCMD), a vacuum pump was added on the permeate side of the original DCMD to generate a vacuum state and a total pressure gradient between the feed and the permeate liquid, resulting in the increase of the membrane flux and decrease of the temperature polarization [14]. Plattner et al. [15] compared VEDCMD with DCMD by purifying groundwater, and the membrane flux of VEDCMD was increased by $42 \%$.

Material-gap membrane distillation (MGMD) is similar to AGMD, except that the air gap between distillation membrane and condensation surface is replaced by other materials, such as sand, deionized water, polyurethane sponge, and the like, to reduce the heat loss and increase the membrane flux. Study of FRANCIS et al. [16] showed that the membrane flux of liquidgap membrane evaporation (LGMD) was $82 \%$ higher than that of AGMD. On the basis of the theoretical analysis and experimental research, it was indicated that the LGMD had higher thermal efficiency, but it was much easier to produce temperature polarization and concentration polarization due to the increase of membrane flux [17].

Multieffect membrane distillation (MEMD) is another novel MD, which is designed to effectively recover the latent heat of phase change by coupling the multieffect evaporation with the traditional MD process, i.e. combining the endothermic evaporation of liquid with the condensation of steam based on the principle of multieffect evaporation. $\mathrm{Li}$ et al. [18] concentrated $2 \%$ dilute sulfuric acid solution to $40 \%$ by multieffect air gap membrane distillation. The membrane flux could reach $5.3 \mathrm{~L} /\left(\mathrm{m}^{2} \cdot \mathrm{h}\right)$, and the conductivity of the distilled solution could be maintained around $150 \mu \mathrm{s} / \mathrm{cm}$ after 30-day continuous experiments.

Vacuum-multieffect membrane distillation (V-MEMD) was first developed by Germany's Memsys water company [14], combining vacuum membrane distillation and multieffect membrane distillation together. Higher membrane flux and lower energy consumption can be achieved by adjusting the system pressure. Mohamed et al. [19] constructed and investigated a vacuum-multieffect membrane distillation system using the commercial membrane of Memsys company. Experiments were conducted with tap and artificial saline water $30 \mathrm{mS} / \mathrm{cm}$ as feed streams. The system performance testing showed that the distillate production can reach $50 \mathrm{~L} / \mathrm{h}$ at $80^{\circ} \mathrm{C}$ of inlet heating water. Andrés-Mañas et al. [20] proposed and evaluated a novel seawater desalination system based on V-MEMD, and the results showed that the four-effect configuration significantly improved the previous V-MEMD system, using the seawater feed flow as the cooling liquid of the condenser instead of a separate circuit.
Bubbling membrane distillation (BMD) is designed to improve the traditional DCMD by bubbling air bubbles into the hot fluid, to enhance its disturbance by the gas-liquid two-phase flow, resulting in the change of the flow pattern from laminar to turbulent flow. Meanwhile, due to the turbulent flow, the thickness of the stagnant inner layer between the hot fluid and the hydrophobic film can be reduced effectively, which is helpful for the improvement of the heat transfer efficiency. Chen et al. [21] studied the formation and influence of bubbles in DCMD. It was found that the gas bubbling not only increased the permeate flux of feed solution from $18 \%$ salt concentration to saturation by an average of $26 \%$ but also delayed the main flux decrease due to crystal deposition. Chen et al. [22] analyzed the mechanism of heat transfer enhancement and scale inhibition of bubbles in MD brine treatment and found that small bubble size and narrow size distribution contributed to generating uniform flow distribution and enhanced surface shear strength; under the optimized bubbling conditions, the heat transfer coefficient of fine bubbles is the highest. Correspondingly, the temperature polarization effect of the membrane is greatly alleviated with the penalty of an unavoidable higher conductive heat loss to the membrane matrix. In order to effectively control the formation of scaling in MD brine concentration process (especially exceeding the supersaturation level), the optimal aeration conditions with smaller average bubble size and narrower bubble size distribution were selected. Wu et al. [23] designed an air bubbling vacuum membrane distillation (AVMD). The results showed that the performance of VMD can be improved by air bubbling with the flow rate being doubled at a certain feed rate and gas-liquid ratio. Zhang et al. [24] investigated the membrane performance and pollution control of an air bubble-assisted blown membrane distillation of high concentration brine $(333 \mathrm{~K}$ saturated solution). The results showed that a longer bubbling interval (3 min) could increase the flux enhancement ratio to 1.518 at a bubbling time of $30 \mathrm{~s}$, and greater flow enhancement can be achieved using the intermittent bubbling system with smaller nozzle size. Kim et al. [25] proposed an air-assisted swirling microbubble generator (MBG), which could improve the permeability of DCMD by $37 \%$ at lower feed temperature and higher feed flow rate and improve the heat and mass transfer performance especially when the microbubbles was less than $100 \mu \mathrm{m}$. The performance of MBG was further evaluated with high concentration brine as the raw material, indicating that it was feasible in practical desalination operation.

The BMD has been proved to be able to enhance the transmembrane performance, but the previous research primarily focused on the enhancement caused by the twophase flow effect, air was nearly the only option for the bubbling gas, and the gas transfer together with the vapor through the hydrophobic membrane was neglected. In this article, we proposed a novel Bubbling and Vacuum-enhanced direct contact membrane distillation process (BVDCMD) combining the BMD and VEDCMD together to enhance the MD performance by the bubbling and transmembrane flow of noncondensable gas, and the 
enhancement is evaluated through CFD simulations of the MD process. In Section 2, the design of a BVDCMD is introduced, including the process construction and the theoretical analysis. In Section 3, a CFD model for the MD is set up and verified by the published experimental data. In Section 4, the enhancement of BVDCMD, the parameter influences as well as the water production rate are predicted.

\section{Design of a BVDCMD Desalination Process}

2.1. Equipment Composition and Working Principle. The Bubbling and Vacuum-enhanced direct contact membrane distillation (BVDCMD) combines the BMD and VEDCMD together to enhance the MD performance by the bubbling and transmembrane flow of the noncondensable gas. Figure 1 shows the flow chart of the seawater desalination process based on BVDCMD. The process is mainly composed of a seawater circuit, a fresh water circuit, a noncondensable gas circuit, and an MD unit. High-temperature seawater at atmospheric pressure is pumped into the MD unit as the feed flow, the noncondensable gas is bubbled into the feed through several nozzles, and the low-temperature fresh water under a certain vacuum degree is pumped into the permeate side of the MD unit. Due to the total and vapor pressure difference, a portion of water vapor and noncondensable gas flows through the membrane from the feed to the permeate side; the water vapor is condensed when it encounters the low-temperature fresh water, and the noncondensable gas flows up and discharges from the MD unit. A water tank isolated from the outside atmosphere is filled with water and a small volume of air, which is maintained under a certain vacuum degree by a suction pump to create a low-pressure state for the fresh water flow. Two heat exchangers are used to preheat the seawater before it goes into the MD unit by discharged noncondensable gas and fresh water, respectively. Meanwhile the cycled fresh water is cooled down before it goes into the MD unit, and the noncondensable gas is cooled down after being pressurized to the atmospheric pressure by a compressor with the supersaturated water condensed, separated, and collected as a portion of water product. Necessary parameter monitoring meters (Temperature $T_{1}-T_{6}$, Pressure $P_{1}-P_{3}$, Flow rate $Q_{1}-Q_{5}$ ) are arranged to test the temperature, pressure, and flow rate of each circuit at certain position shown in Figure 1, and data are also used for the control of the valves to maintain the setting value of each parameter under given conditions.

\subsection{Theoretical Analysis on the Transmembrane Process}

2.2.1. Mass Transfer. The basic configuration of traditional MD desalination is that two independent flow passages are formed by a hydrophobic and breathable membrane with hot sea water on the feed side and cold pure water on the permeation side, and both sides are operated under the atmospheric pressure. The driving force of mass transfer is dominated by the vapor pressure difference between two sides of the membrane. In the transmembrane mass transfer of $\mathrm{MD}$, the permeation flux $J_{\mathrm{M}}\left(\mathrm{kg} \cdot \mathrm{m}^{-2} \cdot \mathrm{s}^{-1}\right)$ is directly proportional to the differential pressure of water vapor on both sides of the membrane [26] as indicated by

$$
J_{\mathrm{M}}=K_{\mathrm{M}}\left(P_{\mathrm{F}, \mathrm{W}}-P_{\mathrm{P}, \mathrm{W}}\right) \text {, }
$$

where $P_{\mathrm{F}, \mathrm{W}}(\mathrm{Pa})$ and $P_{\mathrm{P}, \mathrm{W}}(\mathrm{Pa})$ are the partial pressure of water vapor on the feed side and the permeate side, respectively. The subscript " $F$ " and " $P$ " indicate the parameter of feed and permeate side, respectively, and the subscript " $\mathrm{W}$ " and " $\mathrm{M}$ " indicates the parameter of membrane surface and membrane. $P_{\mathrm{F}, \mathrm{W}}(\mathrm{Pa})$ can be calculated from equation (2), in which $\gamma_{\mathrm{w}}$, the activity coefficient of water at different concentrations, can be obtained from the empirical formula given in equation (3) [24]; $X_{\mathrm{NaCl}}$, the mole fraction of sodium chloride in the solution, can be calculated from equation (4) according to the mass concentration of brine, and $P_{\mathrm{V}} \mathrm{S}(T)(\mathrm{Pa})$, the saturated vapor pressure of pure water at temperature $T(\mathrm{~K})$, can be obtained from Antoine equation (5).

$$
\begin{gathered}
P_{\mathrm{F}, \mathrm{W}}=\left(1-X_{\mathrm{NaCl}}\right) P_{\mathrm{VS}}\left(T_{\mathrm{F}, \mathrm{W}}\right) \gamma_{\mathrm{w}}, \\
\gamma_{\mathrm{w}}=1-0.5 X_{\mathrm{NaCl}}-10 X_{\mathrm{NaCl}}^{2}, \\
X_{\mathrm{NaCl}}=\frac{\left(W_{\mathrm{NaCl}} / M_{\mathrm{NaCl}}\right)}{\left(W_{\mathrm{NaCl}} / M_{\mathrm{NaCl}}\right)}+\frac{W_{\mathrm{w}}}{M_{\mathrm{w}}}, \\
P_{\mathrm{VS}}(T)=23.1964-\frac{3816.44}{T-46.13} .
\end{gathered}
$$

Knudsen number $K_{n}$ defined by equation (6) is usually used to quantitatively determine the relationship between membrane pore size and molecular mean free path, based on which the transmembrane mass transfer model was proposed by Ibrahim et al. [26] and applied widely in the theoretical analysis of MD mass transfer.

$$
K_{\mathrm{n}}=\frac{\lambda}{d}
$$

where $\lambda(m)$ is the average free path of water vapor in air and $d(m)$ is the diameter of membrane hole.

(1) When $K_{\mathrm{n}}>1$, the collision between diffusion molecules and the wall of membrane pore is dominant, and the mass transfer coefficient of membrane distillation $\mathrm{KMD}\left(\mathrm{kg} \cdot \mathrm{m}^{-2} \cdot \mathrm{s}^{-1} \cdot \mathrm{Pa}^{-1}\right)$ can be expressed by

$$
K_{\mathrm{M}}=K_{\mathrm{MD}}=\frac{D_{\mathrm{Wa}} \varepsilon}{\tau \delta} \frac{P M_{\mathrm{w}}}{R T_{\mathrm{M}}},
$$

(2) When $K_{\mathrm{n}}<0.01$, the collision between molecules is dominant. Once there is a gradient of concentration or temperature, different kinds of molecules will produce relative motion and molecular diffusion-dominated mass transfer in the negative direction of the gradient. In this case, the membrane distillation coefficient $K_{\mathrm{K}}\left(\mathrm{kg} \cdot \mathrm{m}^{-2} \cdot \mathrm{s}^{-1} \cdot \mathrm{Pa}^{-1}\right)$ can be expressed as

$$
K_{\mathrm{M}}=K_{\mathrm{K}}=\frac{2}{3} \frac{\mathrm{r} \varepsilon}{\tau \delta}\left(\frac{8 M_{\mathrm{w}}}{\pi R T_{\mathrm{M}}}\right)^{0.5}
$$




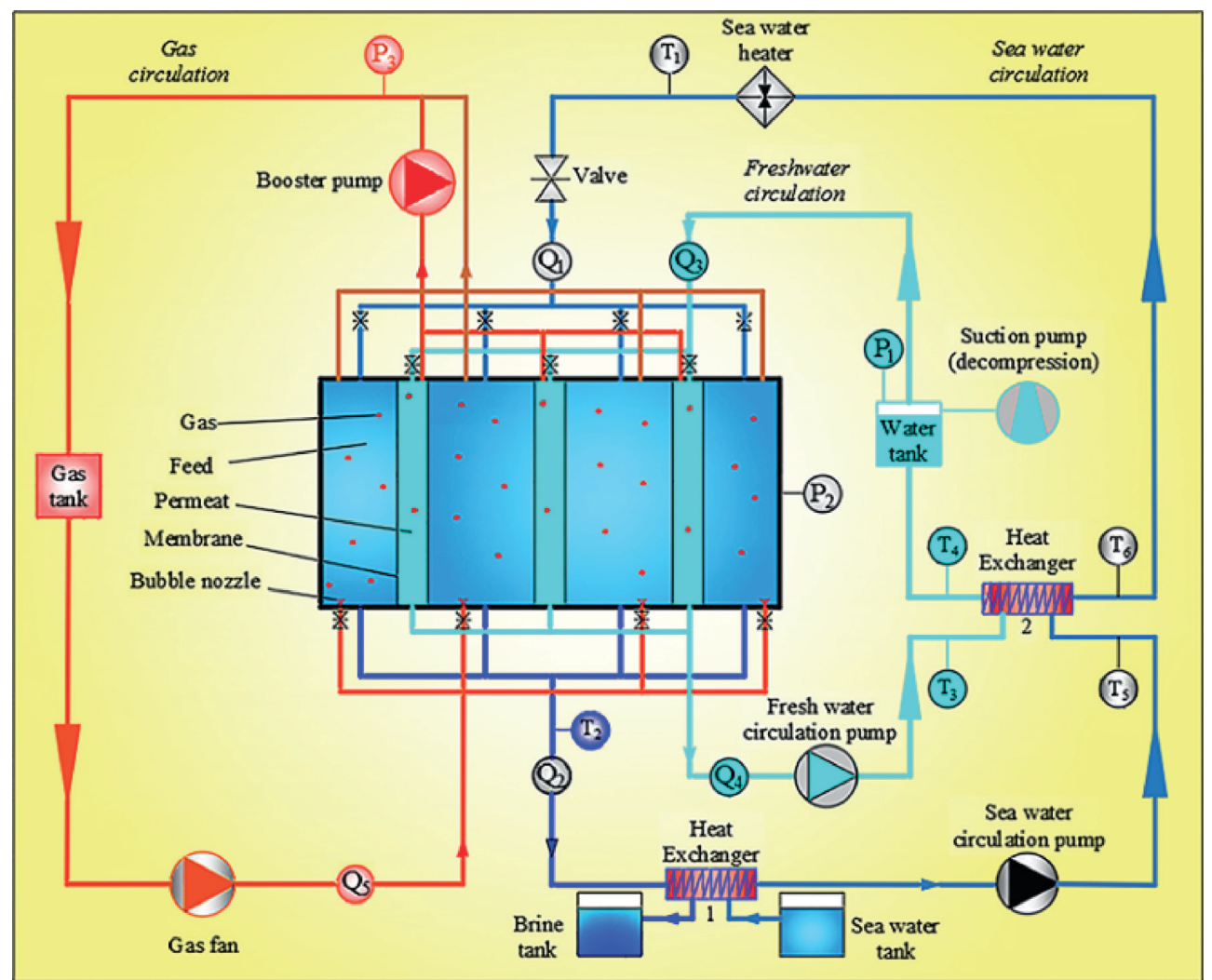

Figure 1: Flow chart of the seawater desalination process based on BVDCMD. $T_{1} \sim T_{6}$ : the temperature of feed inlet, feed outlet, permeate outlet, permeate inlet, and inlet and outlet of heat exchanger 2, respectively. $P_{1} \sim P_{3}$ : the pressure of freshwater, seawater, and gas. $Q_{1} \sim Q_{5}$ : the flow rate of feed inlet, feed outlet, permeate inlet, permeate outlet, and gas inlet.

(3) When $0.01<K_{\mathrm{n}}<1$, the mass transfer resistance is caused by the collision between molecules and the collision between molecules and the wall of membrane pore. In this case, the membrane distillation coefficient adopts Knudsen molecular diffusion model, and the membrane distillation coefficient $K_{\mathrm{K}^{-}}$ $M_{\mathrm{D}}\left(\mathrm{kg} \cdot \mathrm{m}^{-2} \cdot \mathrm{s}^{-1} \cdot \mathrm{pa}^{-1}\right)$ can be expressed as

$$
K_{\mathrm{M}}=K_{\mathrm{K}-\mathrm{MD}}=\left(\frac{1}{K_{\mathrm{K}}}+\frac{1}{K_{\mathrm{MD}}}\right)^{-1} .
$$

If there is a total pressure gradient between the two sides of membrane, the gas in the hole will flow in the negative direction of the gradient as a continuous medium. The membrane distillation coefficient related to Poiseuille flow $K_{\mathrm{PO}}\left(\mathrm{kg} \cdot \mathrm{m}^{-2} \cdot \mathrm{s}^{-1} \cdot \mathrm{pa}^{-1}\right)$ can be expressed as equation (10) [27].

$$
K_{\mathrm{PO}}=\frac{1}{8 \mu} \frac{r^{2} \varepsilon}{\tau \delta} \frac{M_{\mathrm{w}} P_{\mathrm{F}, \mathrm{W}}}{R T_{\mathrm{M}}} .
$$

In the proposed BVDCMD process, the feed side flow is no longer just one-phase liquid flow but a two-phase flow of hot seawater and noncondensable gas. The permeate side flow is under a certain degree of vacuum and liquid flow at first and then develops to a two-phase flow of low-temperature fresh water and noncondensable gas due to the
Poiseuille flow in the pore of membrane caused by total pressure difference between the feed and permeate side similarly to the principle of aeration. Together with the transmembrane flow of the noncondensable gas, some portion of vapor can also be carried from the feed to the permeate side. Thus, the transmembrane mass transfer of water will be driven by not only the difference of vapor pressure but also the difference in total pressure, and the mass transfer can be strengthened. The transmembrane permeation flux of water $J_{M}\left(\mathrm{~kg} \cdot \mathrm{m}^{-2} \cdot \mathrm{s}^{-1}\right)$ can be expressed as

$$
\begin{aligned}
J_{\mathrm{M}}= & \left(K_{\mathrm{K}-\mathrm{MD}}+K_{\mathrm{PO} 1}\right) \cdot\left(P_{\mathrm{F}, \mathrm{W}}-P_{\mathrm{P}, \mathrm{W}}\right) \cdot(1-\Phi) \\
& +\left[K_{\mathrm{K}-\mathrm{MD}} \cdot\left(P_{\mathrm{F}, \mathrm{W}}-P_{\mathrm{P}, \mathrm{W}}\right)+K_{\mathrm{PO} 2} \cdot\left(P_{\mathrm{F}}-P_{\mathrm{P}}\right)\right] \Phi,
\end{aligned}
$$

where $P_{\mathrm{F}}(\mathrm{Pa})$ and $P_{\mathrm{P}}(\mathrm{Pa})$ are the total pressure on the feed and permeate side, respectively; $\Phi$ is the effective strengthening area coefficient, i.e. the ratio of the membrane area occupied by the gas to that occupied by the liquid; $K_{\mathrm{PO} 1}$ and $K_{\mathrm{PO} 2}$ are the mass transfer coefficients in pure steam and mixed gas environments, respectively, and can be calculated by equations (12) and (13), where $\mu_{\mathrm{v}}(\mathrm{Pa} \cdot \mathrm{s})$ and $\mu_{\text {mix }}(\mathrm{Pa} \cdot \mathrm{s})$ are the viscosity of pure steam and mixed gas at different temperatures, respectively, and can be calculated by equations (14) and (15). 


$$
\begin{aligned}
K_{\mathrm{PO} 1} & =\frac{1}{8 \mu_{\mathrm{V}}} \frac{r^{2} \varepsilon}{\tau \delta} \frac{M_{\mathrm{w}} P_{\mathrm{F}, \mathrm{W}}}{R T_{\mathrm{M}}}, \\
K_{\mathrm{PO} 2} & =\frac{1}{8 \mu_{\mathrm{mix}}} \frac{r^{2} \varepsilon}{\tau \delta} \frac{M_{\mathrm{w}} P_{\mathrm{F}, \mathrm{W}}}{R T_{\mathrm{M}}}, \\
\mu & =\mu_{0} \frac{273+S u}{T+S u}\left(\frac{T}{273}\right)^{1.5}, \\
\mu_{\text {mix }} & =\frac{P_{\mathrm{F}, \mathrm{W}} \cdot \mu_{\mathrm{V}}}{P_{0}}+\frac{\left(P_{0}-P_{\mathrm{F}, \mathrm{W}}\right) \cdot \mu_{\mathrm{g}}}{P_{0}},
\end{aligned}
$$

where $\mu_{0}(\mathrm{~Pa} \cdot \mathrm{s})$ and $\mathrm{Su}(\mathrm{K})$ are the dynamic viscosity of the gas at $0^{\circ} \mathrm{C}$ and Suzlon constant depending on the gas type, respectively; $P_{0}$ is the standard atmospheric pressure; $\mu \mathrm{g}$ ( $\mathrm{Pa} \cdot \mathrm{s})$ is the viscosity of the bubbling gas and also can be calculated by equation (14).

The mass transfer effect of noncondensable gas in MD process is investigated by the enhanced mass transfer efficiency FI (Flux Improvement Efficiency), which can be calculated by equation (16) [21].

$$
\mathrm{FI}=\frac{J_{\mathrm{BV}}-J_{\mathrm{D}}}{J_{\mathrm{D}}} \%
$$

where $J_{\mathrm{BV}}\left(\mathrm{kg} \cdot \mathrm{m}^{-2} \cdot \mathrm{h}^{-1}\right)$ is the flux of enhancement and $J_{\mathrm{D}}$ $\left(\mathrm{kg} \cdot \mathrm{m}^{-2} \cdot \mathrm{h}^{-1}\right)$ is the flux of no enhancement.

2.2.2. Heat Transfer. In MD process, transmembrane heat transfer is in the form of phase change and conduction and the transferred heat $q_{\mathrm{M}}\left(\mathrm{w} \cdot \mathrm{m}^{-2}\right)$ can be calculated by equation (17) [26].

$$
q_{\mathrm{M}}=q_{\mathrm{H}}+q_{\mathrm{C}}=J_{\mathrm{M}} \Delta H_{\mathrm{V}}+\frac{\kappa_{\mathrm{M}}}{\delta}\left(T_{\mathrm{F}, \mathrm{W}}-T_{\mathrm{P}, \mathrm{W}}\right),
$$

where $q_{\mathrm{H}}\left(\mathrm{w} \cdot \mathrm{m}^{-2}\right)$ is the heat flow through the membrane and $q_{\mathrm{C}}\left(\mathrm{w} \cdot \mathrm{m}^{-2}\right)$ is the heat transfer by conduction across membrane as heat loss, and $\delta(\mathrm{m})$ is the membrane thickness; $\Delta H_{\mathrm{V}}\left(\mathrm{kJ} \cdot \mathrm{kg}^{-1}\right)$, the enthalpy of water evaporation, can be calculated by equation (18). Due to the presence of gas in the membrane pore, the thermal conductivity of the membrane $\kappa_{\mathrm{M}}\left(\mathrm{J} \cdot \mathrm{m}^{-1} \cdot \mathrm{k}^{-1}\right)$ can be calculated by equation (19).

$$
\begin{aligned}
\Delta H_{\mathrm{V}}= & -0.001351 T_{\mathrm{F}, \mathrm{W}}^{2} \\
& -1.4461 T_{\mathrm{F}, \mathrm{W}}+2986.5, \\
\kappa_{\mathrm{M}}= & \varepsilon \kappa_{\mathrm{a}}+(1-\varepsilon) \kappa_{\mathrm{s}},
\end{aligned}
$$

where $\varepsilon$ is the porosity of membrane, $\kappa_{\mathrm{a}}\left(\mathrm{J} \cdot \mathrm{m}^{-1} \cdot \mathrm{k}^{-1}\right)$ is the thermal conductivity of air, and $\kappa_{\mathrm{s}}\left(\mathrm{J} \cdot \mathrm{m}^{-1} \cdot \mathrm{k}^{-1}\right)$ is the thermal conductivity of $\mathrm{NaCl}$ solid.

The evaporation efficiency (EE) is the ratio of the heat that is helpful for evaporation to the total transmembrane heat transfer, which was defined by [28]

$$
\mathrm{EE}=\frac{J_{\mathrm{M}} \Delta H_{\mathrm{V}}}{J_{\mathrm{M}} \Delta H_{\mathrm{V}}+\kappa_{\mathrm{M}} / \delta\left(T_{\mathrm{F}, \mathrm{W}}-T_{\mathrm{P}, \mathrm{W}}\right)} .
$$

Temperature polarization, which occurs in both the feed side and the permeate side of MD unit, is caused by the thermal boundary layer near the membrane. Generally, temperature polarization coefficient (TPC) is used to quantitatively describe the degree of temperature polarization, which was defined by [28]

$$
\mathrm{TPC}=\frac{T_{\mathrm{F}, \mathrm{M}}-T_{\mathrm{P}, \mathrm{M}}}{T_{\mathrm{F}, \mathrm{B}}-T_{\mathrm{P}, \mathrm{B}}},
$$

where the subscript " $\mathrm{B}$ " indicates the parameter of main body.

2.2.3. Water Production Loss Caused by Noncondensable Gas. After the noncondensable gas and vapor enter the lowtemperature fresh water area at the permeate side through the membrane pore, the vapor is condensed and the gas flows with the permeate flow and then is discharged from the MD unit. The discharged noncondensable gas is in a saturated moist state, i.e. it carries a portion of water vapor out of the MD unit, resulting in a water production loss $J_{\mathrm{wl}}$ $\left(\mathrm{kg} \cdot \mathrm{m}^{-2} \cdot \mathrm{h}^{-1}\right)$, which equal to the difference between the permeate flux of water and water production rate and can be calculated by

$$
J_{\mathrm{wl}}=\frac{P_{\mathrm{VS}}(T) \cdot J_{\mathrm{ng}}}{P_{0}-P_{\mathrm{VS}}(T)},
$$

where $J_{\mathrm{ng}}\left(\mathrm{kg} \cdot \mathrm{m}^{-2} \cdot \mathrm{h}^{-1}\right)$ is the mass flow rate of noncondensable gas through the membrane pore and can be calculated by

$$
J_{\mathrm{ng}}=\frac{J_{\mathrm{V}} \cdot M_{\mathrm{g}} \cdot\left(P_{0}-P_{\mathrm{F}, \mathrm{W}}\right)}{18 P_{\mathrm{F}, \mathrm{W}}},
$$

where $J_{\mathrm{V}}\left(\mathrm{kg} \cdot \mathrm{m}^{-2} \cdot \mathrm{h}^{-1}\right)$ is the mass of water vapor brought by the noncondensable gas across the membrane in unit time and unit area, which can be determined by the simulation results of gas Intensification.

\section{CFD Model and Verification}

\subsection{Governing Equations}

\subsubsection{Continuity Equation}

$$
\nabla \cdot(\overrightarrow{\rho v})=S_{\mathrm{w}}
$$

Here, $S_{\mathrm{w}}\left(\mathrm{kg} \cdot \mathrm{m}^{-3} \cdot \mathrm{s}^{-1}\right)$ is the quality source term of water. In order to simulate the process of transmembrane mass transfer, it is necessary to load the quality source term of water on the first grid near the membrane on the permeate side $(+)$ and the feed side (-):

$$
S_{\mathrm{w}}= \pm \frac{J_{\mathrm{M}}}{b}
$$

where $b(\mathrm{~m})$ is the thickness of the first grid layer. For the membrane distillation process, the quality source term at the feed side is not only related to the grid temperature at the feed side but also affected by the grid temperature at the permeate side. Therefore, UDF needs to be written to achieve this. 


$$
\frac{\partial}{\partial t}(\rho \mathrm{E})+\nabla \cdot(\vec{v}(\rho \mathrm{E}+P))=\nabla \cdot\left(\kappa_{\mathrm{eff}} \nabla T-\sum_{j} h_{j} \vec{J}_{j}+\left(\overline{\bar{\tau}}_{\text {eff }} \cdot \vec{v}\right)\right)+S_{\mathrm{h}}
$$

where $\kappa_{\text {eff }}$ is effective thermal conductivity, $\vec{J}_{j}$ is the diffusion flux of component $j$, and $S_{\mathrm{h}}$ is volume heat source term.

\subsubsection{Momentum Conservation Equation}

$$
\nabla \cdot(\overrightarrow{\rho \mathrm{v}} \overrightarrow{\rho \mathrm{v}})=-\nabla P+\nabla \cdot(\overline{\bar{\tau}})+\overrightarrow{\rho \mathrm{g}},
$$

where $P(\mathrm{~Pa})$ is the static pressure, $\overline{\bar{\tau}}\left(\mathrm{kg} \cdot \mathrm{m}^{-1} \cdot \mathrm{s}^{-1}\right)$ is the stress tensor and $\overrightarrow{\rho g}$ is the gravitational body force. The momentum change caused by the transmembrane mass is neglected in the equation (27); for the transmembrane mass, flow rate is relatively small compared with the mass flow rate of the feed and permeate channel.

\subsubsection{Transport Equation of Components}

$$
\nabla \cdot\left(\overrightarrow{\rho \mathrm{v}} W_{j}\right)=-\nabla \cdot \vec{J}_{j}+S_{j}
$$

where $W_{j}$ is the mass fraction of the component $j ; \vec{J}_{j}$ $\left(\mathrm{kg} \cdot \mathrm{m}^{-2} \cdot \mathrm{s}^{-1}\right)$ is the diffusion flux of the component $j$, and $S_{j}$ $\left(\mathrm{kg} \cdot \mathrm{m}^{-3} \cdot \mathrm{s}^{-1}\right)$ is the quality source term of the corresponding component $j$.

3.1.5. Transport Equations for the Realizable k-e Model. The modeled transport equations for $k$ and $e$ in the realizable $k$-e model are

$$
\begin{aligned}
& \frac{\partial}{\partial t}(\rho \mathrm{k})+\frac{\partial}{\partial x_{j}}\left(\rho \mathrm{k} \vec{v}_{j}\right)=\frac{\partial}{\partial x_{j}}\left[\left(\mu+\frac{\mu_{\mathrm{t}}}{\sigma_{\mathrm{k}}}\right) \frac{\partial k}{\partial x_{j}}\right]+G_{\alpha}+G_{\mathrm{b}}-\rho e-Y_{\mathrm{M}}+S_{\mathrm{k}}, \\
& \frac{\partial}{\partial t}(\rho \mathrm{e})+\frac{\partial}{\partial x_{j}}\left(\rho \mathrm{e} \vec{v}_{j}\right)=\frac{\partial}{\partial x_{j}}\left[\left(\mu+\frac{\mu_{\mathrm{t}}}{\sigma_{\mathrm{e}}}\right) \frac{\partial e}{\partial x_{j}}\right]+\rho C_{1} \beta e-\rho C_{2} \frac{e^{2}}{k+\sqrt{\mathrm{ve}}}+C_{1 \mathrm{e}} \frac{e}{k} C_{3 \mathrm{e}} G_{\mathrm{b}}+S_{\mathrm{e}},
\end{aligned}
$$

where $G_{\alpha}$ and $G_{\mathrm{b}}$ is the generation of turbulence kinetic energy due to the mean velocity gradients and buoyancy, $Y_{M}$ is the contribution of the fluctuating dilatation in compressible turbulence to the overall dissipation rate, $C_{1}$ and $C_{2}$ are constants, and $\sigma_{\mathrm{k}}$ and $\sigma_{\mathrm{e}}$ are the turbulent Prandtl numbers for $k$ and $e$, respectively. $S_{\mathrm{k}}$ and $S_{\mathrm{e}}$ are user-defined source terms.

\subsection{Verification of CFD Model}

3.2.1. Model Description. The established CFD model for MD simulation is verified by published experimental data from Hwang et al. and Yun et al. [29, 30]. These experiments were carried out in the School of Chemical Engineering and Industrial Chemistry at the University New South Wales. The instruments involved in the experiments were constant temperature heater, MUSTERFLEX double-barreled creeping motion pump, 1-7013/D A/D transducer, MelterToledo electric balance, and refrigeration. The membrane module, which was the key of DCMD, was made from Perspex (polymerized methylmethacrylate). Pure water was used as the permeate liquid. Pure water and high concentration $\mathrm{NaCl}$ solution was used as the feed, respectively.

The 2D geometric model of the experimental MD module is shown in Figure 2. The feed and permeate side are both rectangular flow channels with length of $125 \mathrm{~mm}$, width of $25 \mathrm{~mm}$, and height of $12 \mathrm{~mm}$. The flat membrane is made of PVDF with properties shown in Table 1.
3.2.2. Boundary Conditions. The boundary conditions of the CFD model were set according to the experimental set up as follows:

(i) Inlet of feed and permeate side: velocity inlet

(ii) Outlet of feed and permeate side: pressure outlet

(iii) Membrane surface at both sides: no sliding wall, no mass transfer flux, and its heat flux is calculated by equation (17)

(iv) Other surfaces of the module: no sliding wall, no mass transfer, and heat transfer

3.2.3. Mesh Generation. Map scheme and quadrilateral structured grid were adopted for the mesh generation. Both sides near the membrane were locally refined, and grid independence analysis was carried out. In the optimized model, the thickness of the first grid on both sides of the membrane is $10 \mu \mathrm{m}$, and the growth factor is 1.05 . The total amount of grids is 50196, and the schematic diagram of specific meshing results is shown in Figure 3.

3.2.4. Simulating Verification. The CFD model was verified by comparing the simulating results with the experimental data under the same structural and operating conditions. Figure 4 compares the permeate mass flux between the simulating and the experimental results. Figure 5 compares 


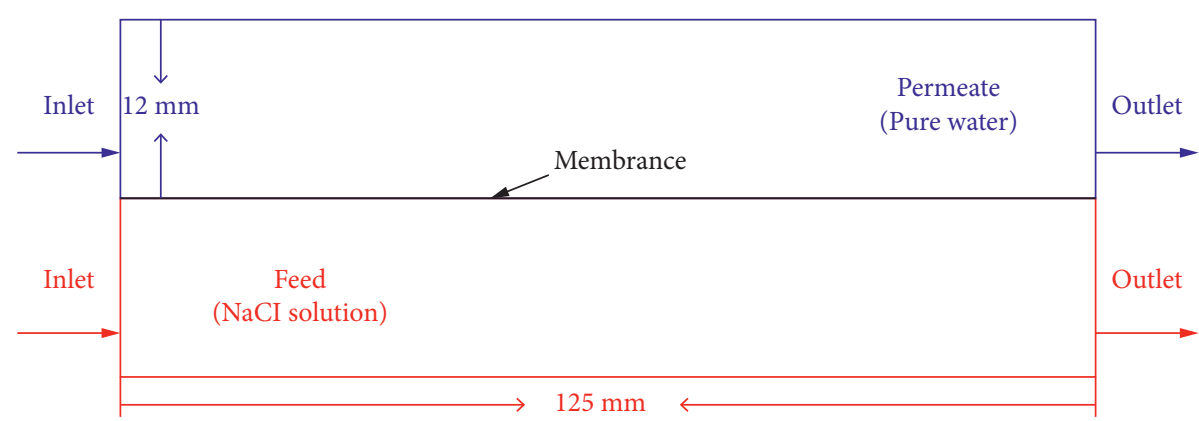

FIgURE 2: 2D geometric model of the experimental MD module.

TABLE 1: Properties of the PVDF membrane.

\begin{tabular}{|c|c|c|c|c|c|}
\hline Length (mm) & Width $(\mathrm{mm})$ & Thickness $(\mu \mathrm{m})$ & Porosity & Pore size $(\mu \mathrm{m})$ & Heat conductivity coefficient $\left(\mathrm{w} \cdot \mathrm{m}^{-1} \cdot \mathrm{k}^{-1}\right)$ \\
\hline 125 & 25 & 120 & 0.75 & 0.22 & 0.0546 \\
\hline
\end{tabular}

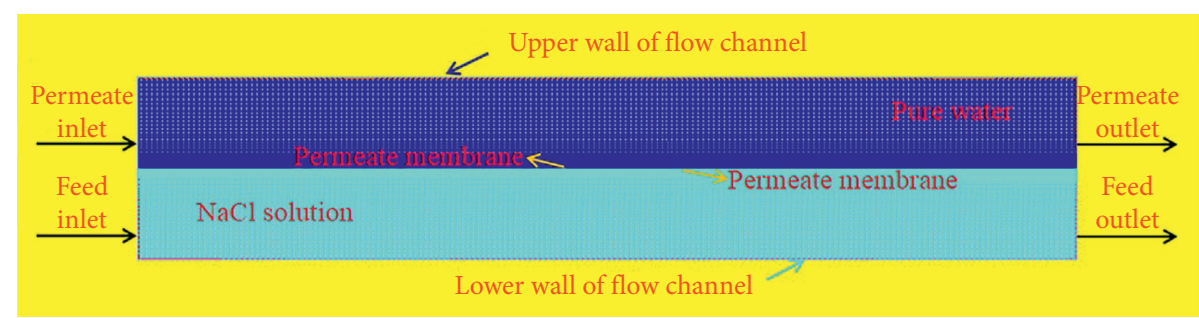

FIGURE 3: Schematic diagram of specific meshing results.

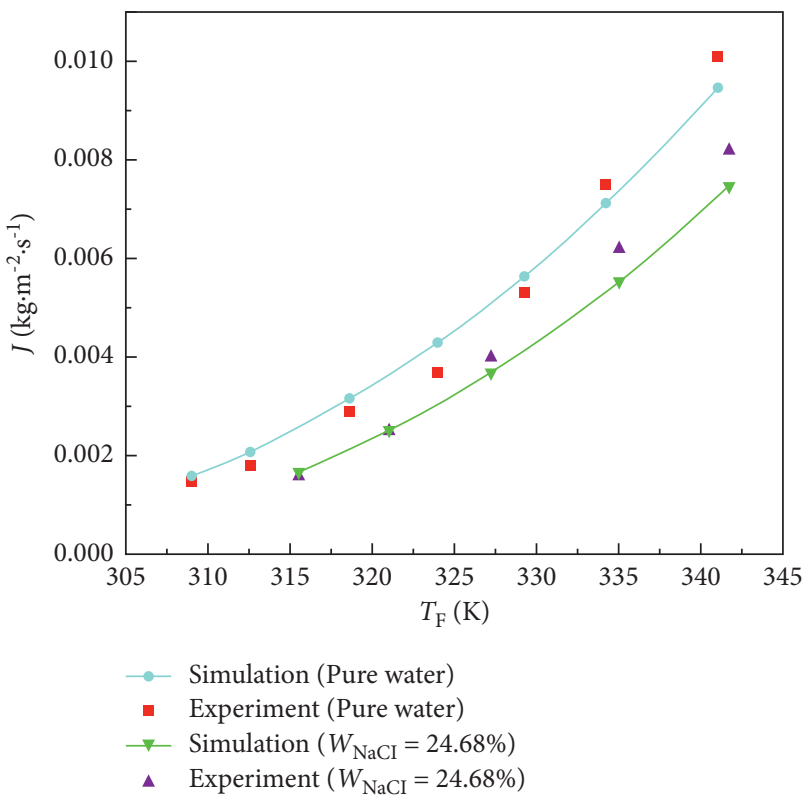

Figure 4: Comparison of permeate mass flux between the simulating results with experimental data. Pure water: $V_{\mathrm{F}}=V_{\mathrm{P}}=0.145 \mathrm{~m} / \mathrm{s}$, $P_{\mathrm{F}}=P_{\mathrm{P}}=P_{0}, T_{\mathrm{P}}=292.7 \mathrm{~K}, W_{\mathrm{NaCl}}=0 ; \mathrm{NaCl}$ solution: $V_{\mathrm{F}}=V_{\mathrm{P}}=0.145 \mathrm{~m} / \mathrm{s}, P_{\mathrm{F}}=P_{\mathrm{P}}=P_{0}, T_{\mathrm{P}}=293.5 \mathrm{~K}, W_{\mathrm{NaCl}}=24.68 \%$.

the simulated temperature of each outlet. The simulated results fit well with the experimental data with the average relative error less than $5 \%$, indicating that the established CFD model is suitable for membrane distillation.

\section{Enhancement Prediction of BVDCMD}

The BVDCMD combines the BMD and VEDCMD together to enhance the MD performance by the bubbling and 


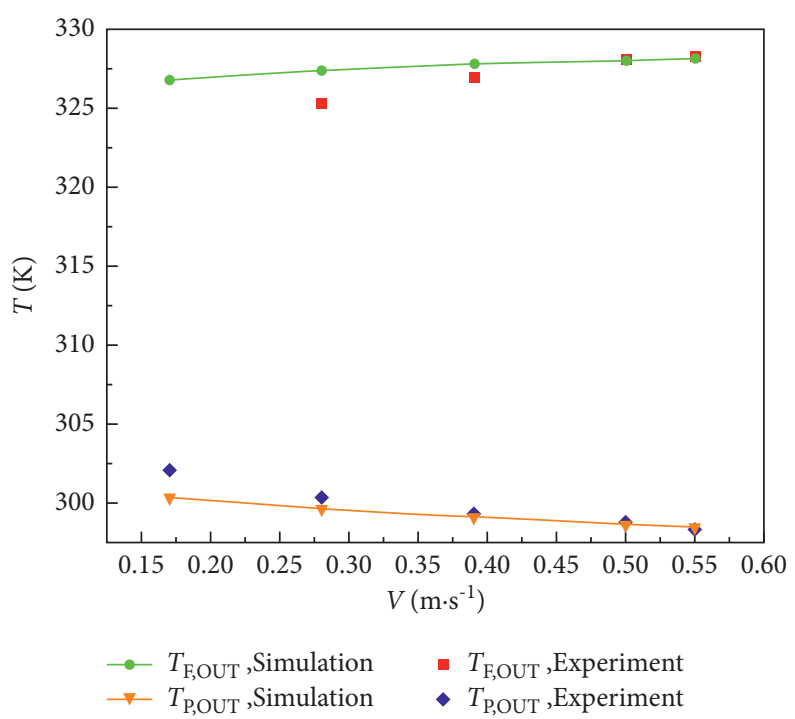

Figure 5: Comparison of outlet temperature between the simulating results and experimental data. $V_{\mathrm{F}}=V_{\mathrm{P}}=V, P_{\mathrm{F}}=P_{\mathrm{P}}=P_{0}, T_{\mathrm{F}}=333 \mathrm{~K}$, $T_{\mathrm{P}}=293 \mathrm{~K}, W_{\mathrm{NaCl}}=1 \%$.

transmembrane flow of the noncondensable gas. In the simulation, " $\mathrm{O}_{2}$," "air," " $\mathrm{N}_{2}$," and " $\mathrm{H}_{2}$ " were chosen as the noncondensable gas, respectively, which were bubbled into the feed side with higher temperature. The total pressure of the feed side flow was maintained to the atmospheric pressure. The total pressure of the permeate side flow was lower to create different extent of vacuum degree, with the range of $3400 \mathrm{~Pa}-101325 \mathrm{~Pa}$. The key performance parameters of BVDCMD process with different types of noncondensable gas as well as that of the DCMD process were obtained by simulating and comparing with the enhancement of the BVDCMD process, under different pressure of permeate side, feed temperature, the $\mathrm{NaCl}$ concentration of the feed side, the flow rate of the feed side, and the permeate side.

\subsection{Enhancement of the Permeate Flux}

4.1.1. Influence of Gas Viscosity and Pressure of the Permeate Side. Figure 6 shows the permeate flux of air bubbling process under different effective enhancement area coefficients $(\Phi)$ and different pressure of the permeate side, and Figure 7 shows the flux improvement efficiency of air bubbling process under different effective enhancement area coefficients $(\Phi)$ and different pressure of the permeate side. With the continuous decrease of pressure difference between the feed side and the permeate side, the permeate fluxes under three effective enhancement area coefficients $(\Phi=0.3$, $0.6,0.9)$ reduce gradually, while the permeate flux of DCMD $(\Phi=0)$ fluctuates slightly and remains basically constant. When the pressure on the permeate side is $90 \mathrm{KPa}$ (close to the atmospheric pressure), the permeate flux under the four conditions are almost the same because the dominant driving force of transmembrane vapor transport is the vapor pressure difference between the two sides of the membrane in this case. When the pressure difference between two sides is the same, the permeate flux increases with the effective enhancement area coefficient $(\Phi)$, and hence, in practice, the bubbling nozzle should be near to the membrane, and the flow state should be adjusted to obtain higher $\Phi$.

Figure 8 shows the permeate flux of four noncondensable gas under different pressure of the permeate side, and Figure 9 shows the flux improvement efficiency of four noncondensable gas under different pressure of the permeate side. With the continuous decrease of pressure difference between the feed side and the permeate side, the permeate fluxes under four kinds of noncondensable gas environment reduce gradually. When the pressure of the permeate side reduces, introducing " $\mathrm{O}_{2}$," "air," " $\mathrm{N}_{2}$," and " $\mathrm{H}_{2}$ " cause obvious permeate flux increase and the enhancement increases with the total pressure difference. Especially, when the pressure of permeate side is $3.4 \mathrm{KPa}$, which is approximately equal to the saturated vapor pressure of water at $25^{\circ} \mathrm{C}$, the permeate flux of " $\mathrm{H}_{2}$ " bubbling process reaches the maximum, about $144.11 \%$ higher than that of DCMD. Moreover, with the decrease in the gas viscosity $\left(\mu_{0}\right)$ of the noncondensable gas, the enhancement effect of the permeate flux become more remarkable. The reason is that the decrease of the viscous flow resistance leads to increase in the total driving force of the transmembrane gas flow. Thus, lower viscosity resistance and larger vacuum degree of the permeate side will be helpful for the enhancement of the permeate flux.

\subsubsection{Influence of Temperature of the Feed Side.} Figure 10 shows the permeate flux under different temperature of the feed side. Under all the conditions, the permeate flux increases almost linearly with the temperature of the feed side, and all the noncondensable gas can enhance the transmembrane mass transfer, in which " $\mathrm{H}_{2}$ " exhibits the best enhancement and " $\mathrm{N}_{2}$ " the second, due to the increase in vapor partial pressure on the feed side and the water vapor carrying ability improvement of noncondensable gas caused by the temperature elevation. 


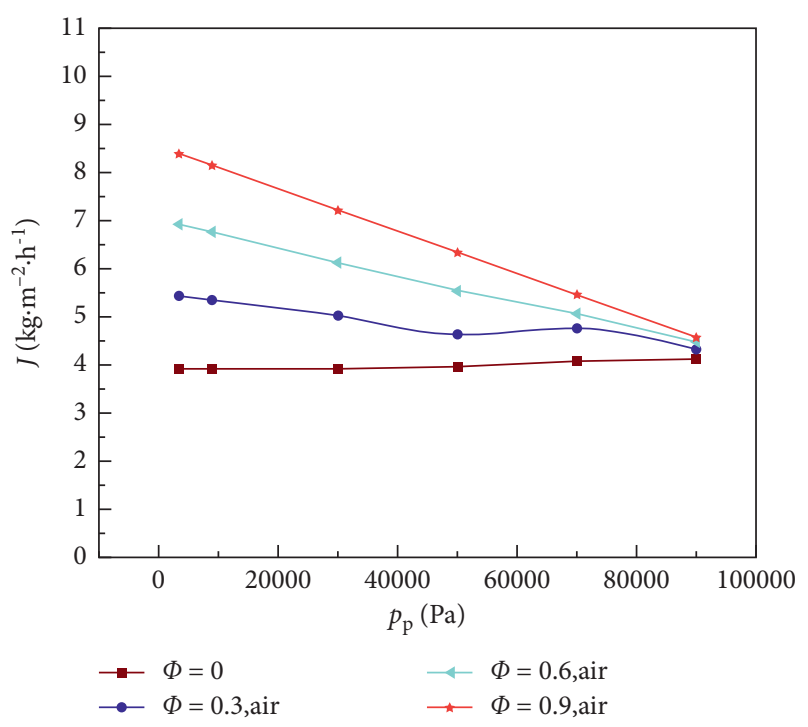

Figure 6: Permeate flux of air bubbling process under different effective enhancement area coefficients $(\Phi)$ and different pressure of the permeate side. $T_{\mathrm{F}, \text { in }}=323 \mathrm{~K}, T_{\mathrm{P}, \text { in }}=298 \mathrm{~K}, V_{\mathrm{F}, \text { in }}=0.145 \mathrm{~m} / \mathrm{s}, V_{\mathrm{P}, \text { in }}=0.002 \mathrm{~m} / \mathrm{s}, P_{\mathrm{F}}=P_{0}, W_{\mathrm{NaCl}}=0$.

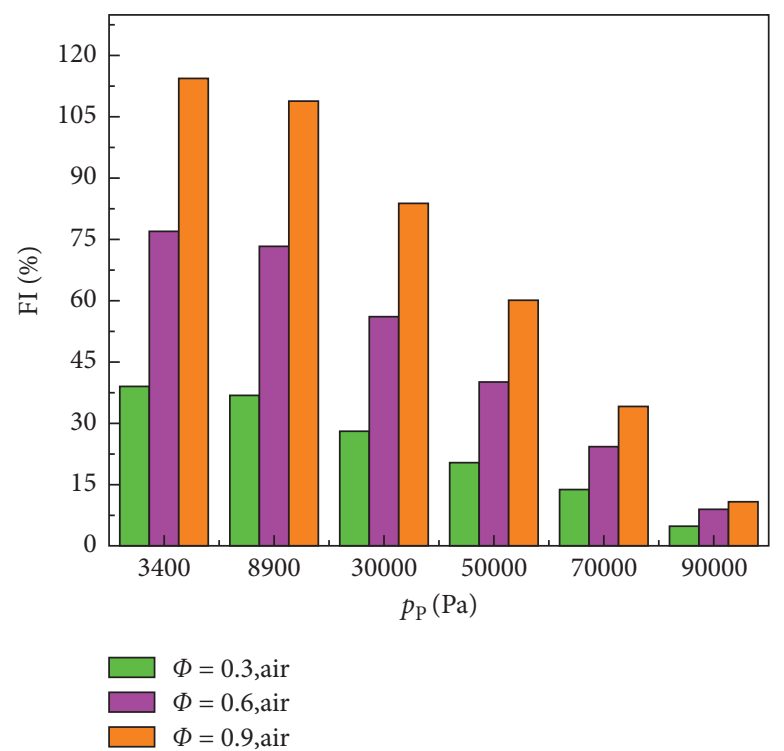

Figure 7: Flux improvement efficiency of air bubbling process under different effective enhancement area coefficients $(\Phi)$ and different pressure of the permeate side. $T_{\mathrm{F}, \text { in }}=323 \mathrm{~K}, T_{\mathrm{P}, \text { in }}=298 \mathrm{~K}, V_{\mathrm{F}, \text { in }}=0.145 \mathrm{~m} / \mathrm{s}, V_{\mathrm{P}, \text { in }}=0.002 \mathrm{~m} / \mathrm{s}, P_{\mathrm{F}}=P_{0}, W_{\mathrm{NaCl}}=0$.

4.1.3. Influence of Different $\mathrm{NaCl}$ Concentrations of the Feed Side. Figure 11 shows the permeate flux under different $\mathrm{NaCl}$ concentration (mass fraction) of the feed side. The permeate flux under all the conditions decrease with the increase in $\mathrm{NaCl}$ concentration, and the introduction of the noncondensable gas with lower viscosity, including " $\mathrm{H}_{2}$ " and " $\mathrm{N}_{2}$," results in obvious flux improvement. The positive variation of the $\mathrm{NaCl}$ concentration could lead to the reduction in the activity of water, the decrease in the partial pressure of water vapor on the feed side, and then the decrease in the transmembrane driving force of mass transfer. In the practice, the increase in concentration also could aggravate the membrane pollution and pore plugging, causing further decrease in the flux with the concentration, and the enhancement of the noncondensable gas will be more remarkable for the reason that the turbulence and the sweeping caused by the two-phase flow could alleviate the membrane pollution and pore plugging.

4.1.4. Influence of Inlet Velocity of Feed and Permeate Sides. Figures 12 and 13 show the permeate flux under different inlet velocity of feed side and the permeate side, respectively. Whether on the feed or the permeate side, the permeate flux increases with the flow velocity in the passage but varies gently with the continuous increase in flow velocity. In the case of lower flow velocity, the fluid flow in the passage is laminar flow resulting in lower mass transfer coefficient. 


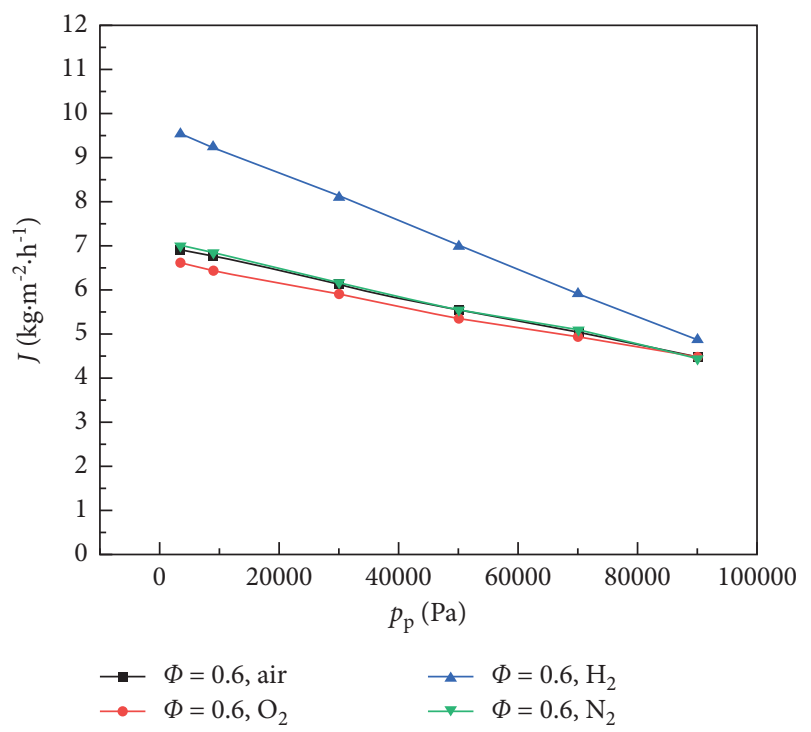

Figure 8: Permeate flux of four noncondensable gas under different pressure of the permeate side. $T_{\mathrm{F}, \text { in }}=323 \mathrm{~K}, T_{\mathrm{P}, \text { in }}=298 \mathrm{~K}$, $V_{\mathrm{F}, \text { in }}=0.145 \mathrm{~m} / \mathrm{s}, V_{\mathrm{P}, \text { in }}=0.002 \mathrm{~m} / \mathrm{s}, P_{\mathrm{F}}=P_{0}, W_{\mathrm{NaCl}}=0$.

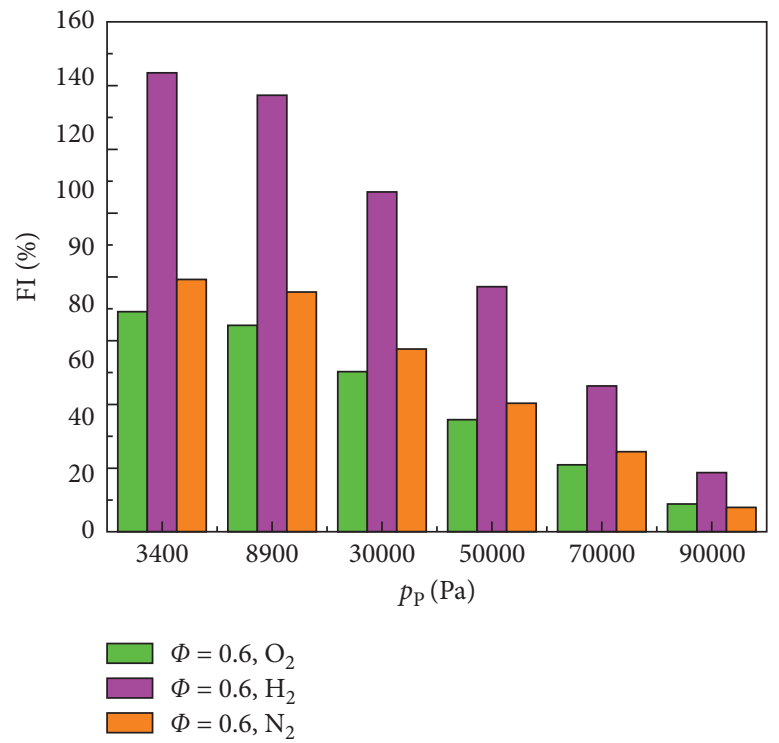

FIGURE 9: Flux improvement efficiency of four noncondensable gas under different pressure of the permeate side. $T_{\mathrm{F}, \text { in }}=323 \mathrm{~K}, T_{\mathrm{P}, \text { in }}=298 \mathrm{~K}$, $V_{\mathrm{F}, \text { in }}=0.145 \mathrm{~m} / \mathrm{s}, V_{\mathrm{P}, \text { in }}=0.002 \mathrm{~m} / \mathrm{s}, P_{\mathrm{F}}=P_{0}, W_{\mathrm{NaCl}}=0$.

With the increase in the velocity, the flow state changes into the turbulence and could significantly reduce the thermal boundary layer on the membrane surface of the feed side, alleviating the temperature and concentration polarization and enhancing the transmembrane mass transfer. When the noncondensable gas introduced in the feed side, the turbulence will generate larger resistance for the gas flow, and it is more difficult to strengthen the gas to pass cross the membrane, resulting in the enhancement decrease. In the CFD model, the gas flow influence on the flow state is not included. However, in the practice, the fluid flow in the passage of both sides can be hardly maintained in the laminar state even when the flow velocity is lower due to the gas flow. Thus, the influence of the inlet velocity on FI might be much weaker than the simulated results.

4.2. Improvement of the Transmembrane Heat Transfer. The evaporation efficiency (EE) and temperature polarization coefficient (TPC) are always used to evaluate the heat transfer performance of MD. Table 2 compares the EE and TPC between DCMD and proposed BVDCMD with " $\mathrm{H}_{2}$ " as the enhancing gas under same conditions. The evaporation efficiency of " $\mathrm{H}_{2}$ " enhanced BVDCMD is significantly higher 


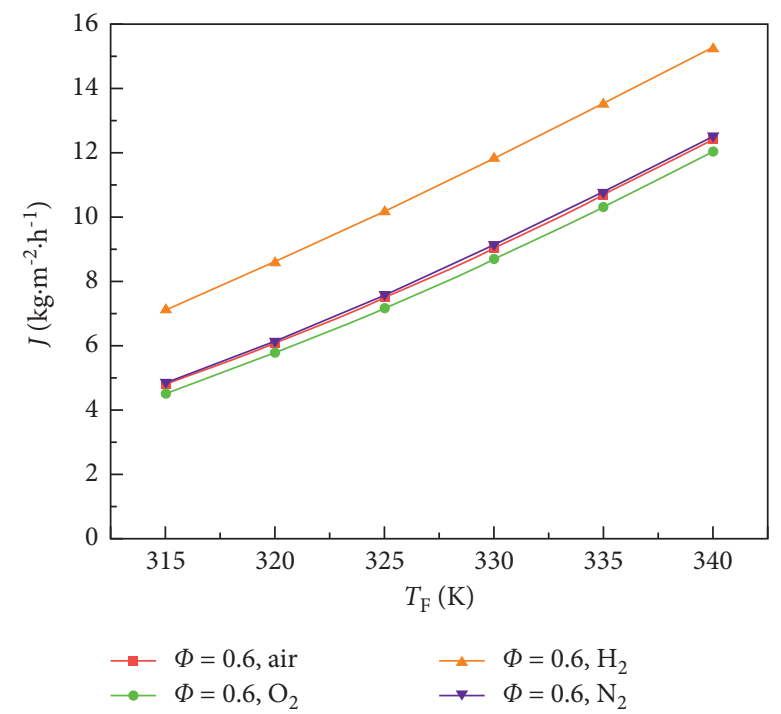

Figure 10: Permeate flux under different temperature of the feed side. $T_{\mathrm{P}, \text { in }}=298 \mathrm{~K}, V_{\mathrm{F}, \text { in }}=0.145 \mathrm{~m} / \mathrm{s}, V_{\mathrm{P}, \text { in }}=0.002 \mathrm{~m} / \mathrm{s}, P_{\mathrm{F}}=P_{0}, P_{\mathrm{P}}=3400 \mathrm{~Pa}$, $W_{\mathrm{NaCl}}=0$.

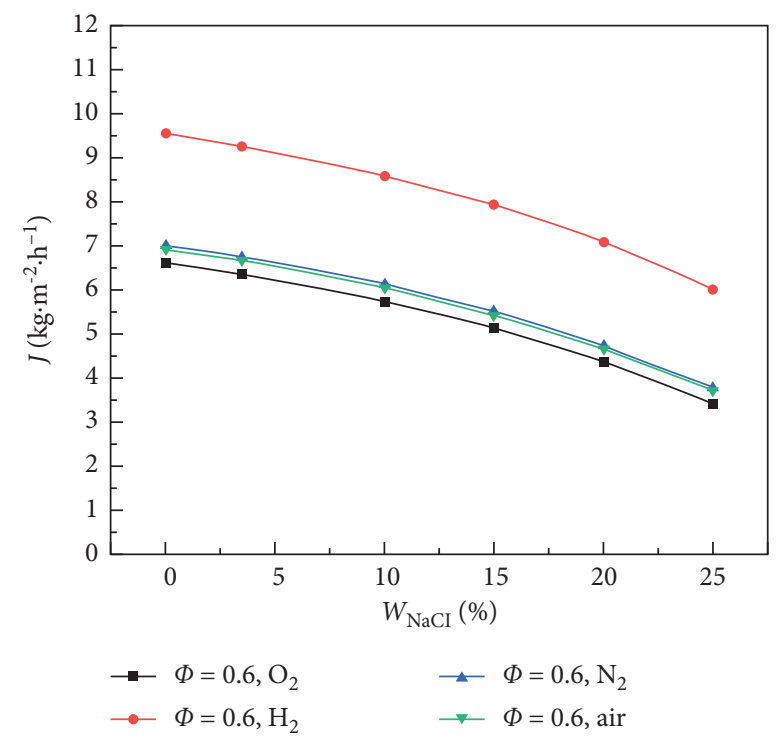

Figure 11: Permeate flux under different $\mathrm{NaCl}$ concentration (mass fraction) of the feed side. $T_{\mathrm{F}, \text { in }}=323 \mathrm{~K}, T_{\mathrm{P}, \text { in }}=298 \mathrm{~K}, V_{\mathrm{F}, \text { in }}=0.145 \mathrm{~m} / \mathrm{s}$, $V_{\mathrm{P}, \text { in }}=0.002 \mathrm{~m} / \mathrm{s}, P_{\mathrm{F}}=P_{0}, P_{\mathrm{P}}=3400 \mathrm{~Pa}$.

than that of DCMD with an average improvement of about $20.81 \%$, indicating the increase in the portion of the effective energy consumption. The evaporation efficiency increases with the feed side velocity for more heat can be used to evaporate the water and decreases with the permeate side velocity for the heat conduction is improved. The temperature polarization coefficient of " $\mathrm{H}_{2}$ " enhanced BVDCMD is slightly lower than that of DCMD, mainly due to the increase in the permeate flux causing more intensive absorption and release of the latent heat near the two surfaces of the membrane. In practice, the two-phase flow will contribute to more turbulent flow with thinner thermal boundary, resulting in an improvement in the temperature polarization coefficient.
4.3. Prediction of Water Production Rate. As mentioned above, in the BVDCMD process, the discharged noncondensable gas will carry a portion of water vapor out of the $\mathrm{MD}$ unit, resulting in a water production loss described by the equation (22), based on which, the water production rate of the BVDCMD seawater desalination system can be predicted. Table 3 shows the predicted water production rate of a BVDCMD seawater ( $\mathrm{NaCl}$ concentration: $3.5 \%)$ desalination system with the membrane area of $1 \mathrm{~m}^{2}$.The average water loss is about $2.05 \%$, i.e. more than $97.5 \%$ of the permeate flux can be converted to the effective water production rate. The BVDCMD can offer a water production rate increase of about $42.38 \%$ compared with the DCMD, in which the water production rate is equal to the permeate 


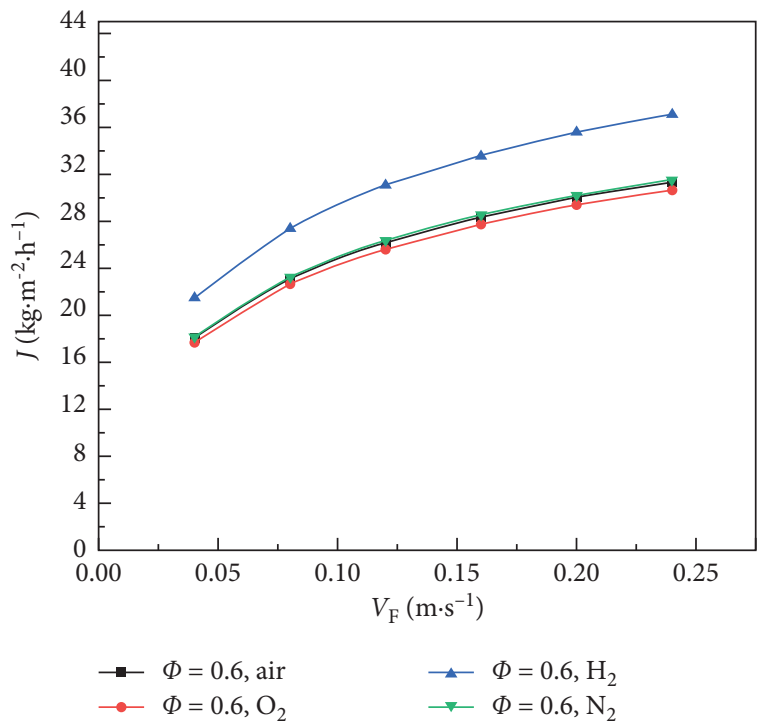

Figure 12: Permeate flux under different inlet velocity of feed side. $T_{\mathrm{F}, \text { in }}=333 \mathrm{~K}, T_{\mathrm{P} \text {,in }}=293 \mathrm{~K}, V_{\mathrm{P} \text {,in }}=0.08 \mathrm{~m} / \mathrm{s}, P_{\mathrm{F}}=P_{0}, P_{\mathrm{P}}=3400 \mathrm{~Pa}$, $W_{\mathrm{NaCl}}=3.5 \%$.

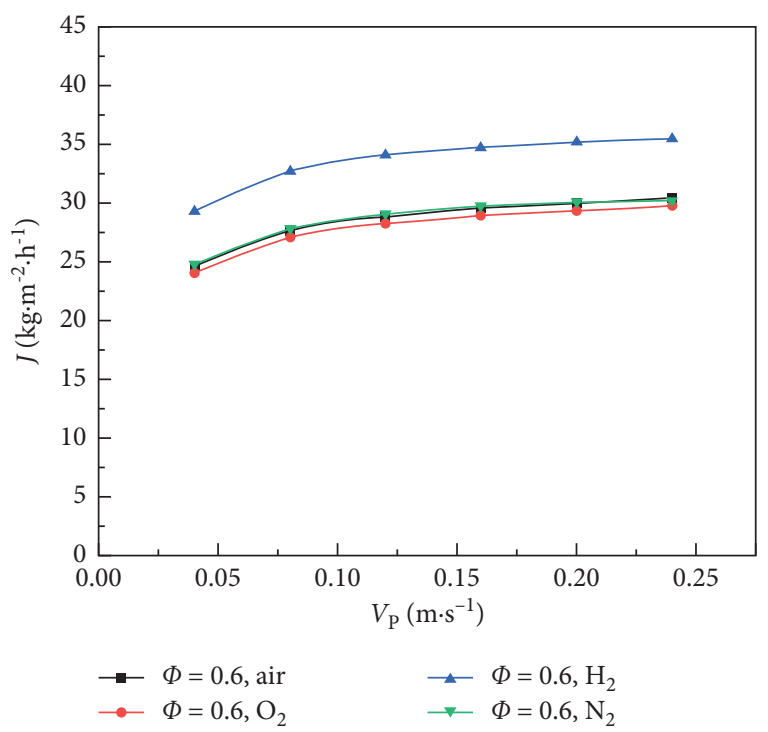

Figure 13: Permeate flux under different inlet velocity of the permeate side. $T_{\mathrm{F}, \text { in }}=333 \mathrm{~K}, T_{\mathrm{P}, \text { in }}=293 \mathrm{~K}, V_{\mathrm{F}, \text { in }}=0.145 \mathrm{~m} / \mathrm{s}, P_{\mathrm{F}}=P_{0}$, $P_{\mathrm{P}}=3400 \mathrm{~Pa}, W_{\mathrm{NaCl}}=3.5 \%$.

Table 2: Performance Parameter analysis.

\begin{tabular}{|c|c|c|c|c|c|c|c|c|c|c|}
\hline \multirow{2}{*}{$W_{\mathrm{NaCl}}(\%)$} & \multicolumn{2}{|c|}{$T(\mathrm{~K})$} & \multicolumn{2}{|c|}{$V(\mathrm{~m} / \mathrm{s})$} & \multicolumn{2}{|c|}{$J\left(\mathrm{~kg} / \mathrm{m}^{2} \cdot \mathrm{h}\right)$} & \multicolumn{2}{|c|}{ EE (\%) } & \multicolumn{2}{|c|}{ TPC } \\
\hline & $T_{\mathrm{F}, \text { in }}$ & $T_{\mathrm{P}, \text { in }}$ & $V_{\mathrm{P}}$ & $V_{\mathrm{F}}$ & DCMD & BVDCMD & DCMD & BVDCMD & DCMD & BVDCMD \\
\hline 3.5 & 333 & 293 & 0.08 & 0.04 & 14.45 & 21.46 & 57.43 & 73.22 & 0.469 & 0.357 \\
\hline 3.5 & 333 & 293 & 0.08 & 0.08 & 18.67 & 27.36 & 61.20 & 75.55 & 0.502 & 0.389 \\
\hline 3.5 & 333 & 293 & 0.08 & 0.12 & 21.21 & 31.01 & 65.25 & 76.90 & 0.519 & 0.404 \\
\hline 3.5 & 333 & 293 & 0.08 & 0.16 & 23.03 & 33.54 & 64.49 & 77.78 & 0.529 & 0.414 \\
\hline 3.5 & 333 & 293 & 0.08 & 0.2 & 24.45 & 35.49 & 65.48 & 78.44 & 0.536 & 0.420 \\
\hline 3.5 & 333 & 293 & 0.08 & 0.24 & 25.55 & 37.04 & 66.21 & 78.94 & 0.542 & 0.425 \\
\hline 3.5 & 333 & 293 & 0.04 & 0.145 & 19.67 & 29.25 & 67.32 & 83.21 & 0.425 & 0.276 \\
\hline 3.5 & 333 & 293 & 0.08 & 0.145 & 22.45 & 32.67 & 64.1 & 77.48 & 0.526 & 0.411 \\
\hline 3.5 & 333 & 293 & 0.12 & 0.145 & 23.60 & 34.04 & 62.35 & 74.73 & 0.581 & 0.482 \\
\hline 3.5 & 333 & 293 & 0.16 & 0.145 & 24.23 & 34.69 & 61.18 & 72.94 & 0.618 & 0.530 \\
\hline 3.5 & 333 & 293 & 0.2 & 0.145 & 24.58 & 35.14 & 60.29 & 71.72 & 0.644 & 0.564 \\
\hline 3.5 & 333 & 293 & 0.24 & 0.145 & 24.84 & 35.43 & 59.65 & 70.82 & 0.665 & 0.589 \\
\hline
\end{tabular}


TABLE 3: Predicted water production rate of a BVDCMD seawater desalination system.

\begin{tabular}{|c|c|c|c|c|c|c|c|c|}
\hline \multirow{2}{*}{$W_{\mathrm{NaCl}}(\%)$} & \multicolumn{2}{|c|}{$T(\mathrm{~K})$} & \multicolumn{2}{|c|}{$V(\mathrm{~m} / \mathrm{s})$} & \multirow{2}{*}{$J_{\mathrm{D}}\left(\mathrm{kg} / \mathrm{m}^{2} \cdot \mathrm{h}\right)$} & \multirow{2}{*}{$J_{\mathrm{BV}}\left(\mathrm{kg} / \mathrm{m}^{2} \cdot \mathrm{h}\right)$} & \multirow{2}{*}{$J_{\mathrm{wl}}\left(\mathrm{kg} / \mathrm{m}^{2} \cdot \mathrm{h}\right)$} & \multirow{2}{*}{$J_{\mathrm{wr}}\left(\mathrm{kg} / \mathrm{m}^{2} \cdot \mathrm{h}\right)$} \\
\hline & $T_{\mathrm{F}, \text { in }}$ & $T_{\mathrm{P}, \text { in }}$ & $V_{\mathrm{P}}$ & $V_{\mathrm{F}}$ & & & & \\
\hline 3.5 & 333 & 293 & 0.08 & 0.04 & 14.45 & 21.46 & 0.455 & 21.005 \\
\hline 3.5 & 333 & 293 & 0.08 & 0.08 & 18.67 & 27.36 & 0.569 & 26.791 \\
\hline 3.5 & 333 & 293 & 0.08 & 0.12 & 21.21 & 31.01 & 0.638 & 30.372 \\
\hline 3.5 & 333 & 293 & 0.08 & 0.16 & 23.03 & 33.54 & 0.687 & 32.853 \\
\hline 3.5 & 333 & 293 & 0.08 & 0.2 & 24.45 & 35.49 & 0.722 & 34.768 \\
\hline 3.5 & 333 & 293 & 0.08 & 0.24 & 25.55 & 37.04 & 0.748 & 36.292 \\
\hline 3.5 & 333 & 293 & 0.04 & 0.145 & 19.67 & 29.25 & 0.627 & 28.623 \\
\hline 3.5 & 333 & 293 & 0.08 & 0.145 & 22.45 & 32.67 & 0.670 & 32.000 \\
\hline 3.5 & 333 & 293 & 0.12 & 0.145 & 23.60 & 34.04 & 0.685 & 33.355 \\
\hline 3.5 & 333 & 293 & 0.16 & 0.145 & 24.23 & 34.69 & 0.695 & 33.995 \\
\hline 3.5 & 333 & 293 & 0.2 & 0.145 & 24.58 & 35.14 & 0.705 & 34.435 \\
\hline 3.5 & 333 & 293 & 0.24 & 0.145 & 24.84 & 35.43 & 0.705 & 34.725 \\
\hline
\end{tabular}

flux. Meanwhile, the two-phase flow in the feed passage of the BVDCMD module due to the introduction of the noncondensable gas can improve the flow state of the boundary near the membrane surface and alleviate the membrane pollution, indicating that the BVDCMD is much more suitable for seawater desalination.

\section{Conclusions}

The membrane distillation (MD) is one of the advanced technologies for seawater desalination, developed in recent years. Due to low flux, membrane wetting and large heat loss, it has not been commercialized in large desalination plants. Thus, lots of efforts have been performed to improve the permeate flux and reduce the energy consumption. In this article, we proposed a Bubbling and Vacuum-enhanced direct contact membrane distillation (BVDCMD) for seawater desalination, considering not only the enhancement of bubbling and vacuum but also the enhancement caused by the transmembrane of the bubbling gas.

Through a series of CFD simulation under different pressure of permeate side, temperature and $\mathrm{NaCl}$ concentration of feed side and flow velocity of both sides, introducing "O2," "air," "N2," and "H2" as the noncondensable bubbling gas, respectively, "H2" was proved to be the best option due to its lower viscosity. Under all the conditions, BVDCMD exhibits a better performance than DCMD, especially when the pressure of permeate side was $3.4 \mathrm{KPa}$, the permeate flux of the "H2" enhancing process reaches the maximum, about $144.11 \%$ higher than that of DCMD. Due to the mass transfer enhancement, the effective heat consumption can be increased by $20.81 \%$ on average, and the effective water production rate of BVDCMD seawater desalination system can be improved by about $42.38 \%$ compared with DCMD, proving the feasibility of BVDCMD in seawater desalination.

In the established CFD model, the influences of the twophase flow were not included. In practice, the two-phase flow will cause more intense turbulence, enhance the transmembrane mass transfer, and alleviate the temperature polarization near the membrane surface, which are beneficial to the performance improvement of the process. In the further study, the two-phase flow effects will be considered and studied through more complicated CFD models and necessary experimental tests, and the proposed BVDCMD for seawater desalination will be verified and continuing improved by experiments.

\section{Patents}

The content of this manuscript has been patented, and the name of the invention: low-viscosity gas bubbling-vacuumenhanced direct contact membrane distillation seawater desalination device.

\section{Nomenclature}

Symbols

J: $\quad$ The permeation flux $\left(\mathrm{kg} \cdot \mathrm{m}^{-2} \cdot \mathrm{s}^{-1}\right)$

K: $\quad$ Membrane distillation coefficient $\left(\mathrm{kg} \cdot \mathrm{m}^{-2} \cdot \mathrm{s}^{-1} \cdot \mathrm{pa}^{-1}\right)$

$P: \quad$ Pressure $(\mathrm{Pa})$

$X_{\mathrm{NaCl}}$ : Molar fraction of solute

T: $\quad$ Temperature (K)

$\gamma: \quad$ Activity coefficient

$W: \quad$ Mass fraction

M: $\quad$ Molar molecular mass $\left(\mathrm{kg} \cdot \mathrm{mol}^{-1}\right)$

$K_{\mathrm{n}}: \quad$ Knudsen number

$\lambda: \quad$ Average free path of water vapor in air (m)

$d$ : Diameter of membrane hole $(\mathrm{m})$

$D_{\mathrm{Wa}}:$ Diffusion coefficient of water in air $\left(\mathrm{m}^{2} \cdot \mathrm{s}^{-1}\right)$

$\varepsilon$ : $\quad$ Porosity

$\tau$ : $\quad$ Membrane tortuosity factor

$\delta: \quad$ Membrane thickness (m)

$R: \quad$ Gas constant $\left(\mathrm{J} \cdot \mathrm{mol}^{-1} \cdot \mathrm{k}^{-1}\right)$

$r$ : Membrane hole radius (m)

$\mu$ : liquid viscosity (pa.s)

$\Phi: \quad$ The effective strengthening area coefficient

$\mu_{0}$ : $\quad$ The dynamic viscosity of the gas at $0^{\circ} \mathrm{C}(\mathrm{pa} \cdot \mathrm{s})$

Su: $\quad$ Susland constant (K)

$P_{0}$ : The standard atmospheric pressure $(\mathrm{Pa})$

FI: $\quad$ Flux improvement efficiency (\%)

$q$ : $\quad$ Heat flux $\left(\mathrm{w} \cdot \mathrm{m}^{-2}\right)$

$\Delta H_{\mathrm{V}}: \quad$ Enthalpy of evaporation $\left(\mathrm{kJ} \cdot \mathrm{kg}^{-1}\right)$

$\kappa: \quad$ Thermal conductivity $\left(\mathrm{J} \cdot \mathrm{m}^{-1} \cdot \mathrm{k}^{-1}\right)$ 
EE: The evaporation efficiency (\%)

TPC: Temperature polarization coefficient

$\rho: \quad$ Density $\left(\mathrm{kg} \cdot \mathrm{m}^{-3}\right)$

$\vec{v}: \quad$ Flow rate $\left(\mathrm{m} \cdot \mathrm{s}^{-1}\right)$

S: $\quad$ Source term

$b$ : The thickness of the first grid layer (m)

$h$ : sensible enthalpy

$\overline{\bar{\tau}}$ : $\quad$ Stress tensor $\left(\mathrm{kg} \cdot \mathrm{m}^{-1} \cdot \mathrm{s}^{-1}\right)$

$\rho \vec{g}: \quad$ The gravitational body force

$k$ : $\quad$ Turbulent kinetic energy equation

$\sigma: \quad$ Turbulent Prandtl number

G: $\quad$ Turbulence kinetic energy

$e: \quad$ Diffusion equation

$Y_{\mathrm{M}}$ : The contribution of the fluctuating dilatation

$C_{1}$ : Constant

$\mathrm{C}_{2}$ : Constant

$C_{1 \mathrm{e}}$ : Constant

$C_{3 \mathrm{e}}$ : Constant

$\beta$ : Coefficient

\section{Superscript}

S: Saturation properties

\section{Subscripts}

M: Membrane

F: $\quad$ Feed side

P: $\quad$ Permeate side

W: Membrane surface

V: $\quad$ Vapor

w: Water

MD: Molecular diffusion

K: $\quad$ Knudsen diffusion

K- Knudsen molecular diffusion

$\mathrm{MD}$ :

PO: Poiseuille flow

PO1: The mass transfer coefficients in pure steam environment

PO2: The mass transfer coefficients in mixed gas environment

mix: the mixed gas

g: $\quad$ Gas

BV: BVDCMD

D: DCMD

$\mathrm{H}$ : Heat convective

C: $\quad$ Heat conduction

a: Air

s: $\quad$ Solid

B: Main body

wl: Water production loss

ng: $\quad$ Noncondensable gas

eff: Effective

$j$ : Component

h: Volume heat

$\alpha$ : The mean velocity gradients

b: buoyancy

t: turbulent

$\mathrm{k}$ : $\quad \mathrm{k}$ equation

e: e equation

wr: Water production rate.

\section{Data Availability}

The data used to support the findings of this study are included within the article.

\section{Conflicts of Interest}

The authors declare no conflicts of interest.

\section{Authors' Contributions}

Guangfu Cao and Qingfen Ma conceptualized the study. Guangfu Cao performed data curation. Guangfu Cao and Qingfen Ma performed formal analysis. Qingfen Ma was responsible for funding acquisition. Guangfu Cao performed investigation. Guangfu Cao, Chengpeng Wang and Qingfen $\mathrm{Ma}$ developed the methodology. Qingfen $\mathrm{Ma}$ performed project administration. Guangfu Cao provided the software. Qingfen Ma and Hui Lu supervised the study. Guangfu Cao performed validation. Guangfu Cao wrote the original draft. Guangfu Cao, Qingfen Ma, Jingru Li, Shenghui Wang, Chengpeng Wang, Hui Lu, and Yun Zheng reviewed and edited the article. Chengpeng Wang and Guangfu Cao have contributed equally to the work.

\section{Acknowledgments}

The financial support by the National Natural Science Foundations of China (51769006) is gratefully acknowledged.

\section{References}

[1] C. Li, Y. Goswami, and E. Stefanakos, "Solar assisted sea water desalination: a review," Renewable and Sustainable Energy Reviews, vol. 19, pp. 136-163, 2013.

[2] M. Shatat, M. Worall, and S. Riffat, "Opportunities for solar water desalination worldwide: review," Sustainable Cities and Society, vol. 9, pp. 67-80, 2013.

[3] M. M. Teoh, T.-S. Chung, and Y. S. Yeo, "Dual-layer PVDF/ PTFE composite hollow fibers with a thin macrovoid-free selective layer for water production via membrane distillation," Chemical Engineering Journal, vol. 171, no. 2, pp. 684-691, 2011.

[4] S. Abdelkader, F. Gross, D. Winter et al., "Application of direct contact membrane distillation for saline dairy effluent treatment: performance and fouling analysis," Environmental Science and Pollution Research, vol. 26, no. 19, pp. 1897918992, 2019.

[5] K. Yao, Y. Qin, Y. Yuan, L. Liu, F. He, and Y. Wu, "A continuous-effect membrane distillation process based on hollow fiber AGMD module with internal latent-heat recovery," AIChE Journal, vol. 59, no. 4, pp. 1278-1297, 2012.

[6] C. Cojocaru and M. Khayet, "Sweeping gas membrane distillation of sucrose aqueous solutions: response surface modeling and optimization," Separation and Purification Technology, vol. 81, no. 1, pp. 12-24, 2011.

[7] Z.-P. Zhao, C.-Y. Zhu, D.-Z. Liu, and W.-F. Liu, "Concentration of ginseng extracts aqueous solution by vacuum membrane distillation 2 . Theory analysis of critical operating conditions and experimental confirmation," Desalination, vol. 267, no. 2-3, pp. 147-153, 2011. 
[8] H. Chamani, T. Matsuura, D. Rana, and C. Q. Lan, "Modeling of pore wetting in vacuum membrane distillation," Journal of Membrane Science, vol. 572, pp. 332-342, 2019.

[9] D. Zhao, J. Zuo, K.-J. Lu, and T.-S. Chung, "Fluorographite modified PVDF membranes for seawater desalination via direct contact membrane distillation," Desalination, vol. 413, pp. 119-126, 2017.

[10] M. Tian, S. Yuan, F. Decaesstecker, J. Zhu, A. Volodine, and B. Van der Bruggen, "One-step fabrication of isotropic pol$\mathrm{y}$ (vinylidene fluoride) membranes for direct contact membrane distillation (DCMD)," Desalination, vol. 477, p. 114265, 2020.

[11] H. Li, W. Shi, X. Zeng, S. Huang, H. Zhang, and X. Qin, "Improved desalination properties of hydrophobic GO-incorporated PVDF electrospun nanofibrous composites for vacuum membrane distillation," Separation and Purification Technology, vol. 230, p. 115889, 2020.

[12] J. E. Efome, D. Rana, T. Matsuura, and C. Q. Lan, "Enhanced performance of PVDF nanocomposite membrane by nanofiber coating: a membrane for sustainable desalination through MD," Water Research, vol. 89, pp. 39-49, 2016.

[13] J. E. Efome, D. Rana, T. Matsuura, F. Yang, Y. Cong, and C. Q. Lan, “Triple-layered nanofibrous metal-organic framework-based membranes for desalination by direct contact membrane distillation," ACS Sustainable Chemistry \& Engineering, vol. 8, no. 17, pp. 6601-6610, 2020.

[14] D. González, J. Amigo, and F. Suárez, "Membrane distillation: perspectives for sustainable and improved desalination," Renewable and Sustainable Energy Reviews, vol. 80, pp. 238259, 2017.

[15] J. Plattner, G. Naidu, T. Wintgens, S. Vigneswaran, and C. Kazner, "Fluoride removal from groundwater using direct contact membrane distillation (DCMD) and vacuum enhanced DCMD (VEDCMD)," Separation and Purification Technology, vol. 180, pp. 125-132, 2017.

[16] L. Francis, N. Ghaffour, A. A. Alsaadi, and G. L. Amy, "Material gap membrane distillation: a new design for water vapor flux enhancement," Journal of Membrane Science, vol. 448, pp. 240-247, 2013.

[17] M. Essalhi and M. Khayet, "Application of a porous composite hydrophobic/hydrophilic membrane in desalination by air gap and liquid gap membrane distillation: a comparative study," Separation and Purification Technology, vol. 133, pp. 176-186, 2014.

[18] X. J. Li, Y. J. Qin, R. L. Liu, Y. P. Zhang, and K. Yao, "Study on concentration of aqueous sulfuric acid solution by multipleeffect membrane distillation," Desalination, vol. 307, pp. 3441, 2020.

[19] E. S. Mohamed, P. Boutikos, E. Mathioulakis, and V. Belessiotis, "Experimental evaluation of the performance and energy efficiency of a vacuum multi-effect membrane distillation system," Desalination, vol. 408, pp. 70-80, 2017.

[20] J. A. Andrés-Mañas, A. Ruiz-Aguirre, F. G. Acién, and G. Zaragoza, "Assessment of a pilot system for seawater desalination based on vacuum multi-effect membrane distillation with enhanced heat recovery," Desalination, vol. 443, pp. 110-121, 2018.

[21] G. Chen, X. Yang, R. Wang, and A. G. Fane, "Performance enhancement and scaling control with gas bubbling in direct contact membrane distillation," Desalination, vol. 308, pp. 47-55, 2013.

[22] G. Chen, X. Yang, Y. Lu, R. Wang, and A. G. Fane, "Heat transfer intensification and scaling mitigation in bubbling- enhanced membrane distillation for brine concentration," Journal of Membrane Science, vol. 470, pp. 60-69, 2014.

[23] C. Wu, Z. Li, J. Zhang, Y. Jia, Q. Gao, and X. Lu, "Study on the heat and mass transfer in air-bubbling enhanced vacuum membrane distillation," Desalination, vol. 373, pp. 16-26, 2015.

[24] D. Zhang, X. Zhang, L. Chen et al., "Effect of bubble characteristics and nozzle size on the membrane distillation enhanced by gas-liquid two-phase flow," Journal of Water Reuse and Desalination, vol. 9, no. 3, pp. 292-300, 2019.

[25] Y.-B. Kim, H.-S. Lee, L. Francis, and Y.-D. Kim, "Innovative swirling flow-type microbubble generator for multi-stage DCMD desalination system: focus on the two-phase flow pattern, bubble size distribution, and its effect on MD performance," Journal of Membrane Science, vol. 588, Article ID 117197, 2019.

[26] S. S. Ibrahim and Q. F. Alsalhy, "Modeling and simulation for direct contact membrane distillation in hollow fiber modules," AIChE Journal, vol. 59, no. 2, pp. 589-603, 2013.

[27] R. W. Schofield, A. G. Fane, and C. J. D. Fell, "Heat and mass transfer in membrane distillation," Journal of Membrane Science, vol. 33, no. 3, pp. 299-313, 1987.

[28] S. Chhun, W. Khongnakorn, and W. Youravong, "Energy consumption for brine solution recovery in direct contact membrane distillation," Advanced Materials Research, vol. 931-932, pp. 256-260, 2014.

[29] Y. Yun, R. Ma, W. Zhang, A. G. Fane, and J. Li, "Direct contact membrane distillation mechanism for high concentration $\mathrm{NaCl}$ solutions," Desalination, vol. 188 , no. 1-3, pp. 251-262, 2006.

[30] H. J. Hwang, K. He, S. Gray, J. Zhang, and I. S. Moon, "Direct contact membrane distillation (DCMD): experimental study on the commercial PTFE membrane and modeling," Journal of Membrane Science, vol. 371, no. 1-2, pp. 90-98, 2011. 